\title{
La Gran Depresión Americana y su influencia en el desarrollo de la fotografía social: "la Amé- rica más mísera"
}

\author{
Íñigo SARRIUGARTE GÓMEZ \\ Universidad del País Vasco
}

\begin{abstract}
RESUMEN. A raíz de las consecuencias económicas del fatídico “jueves negro", el 24 de octubre de 1929, el nuevo presidente Roosevelt propuso cuatro años más tarde una serie de medidas socio-económicas, que serían la base para el “New Deal”. Dentro de estas medidas, se incluye la creación del organismo gubernamental "Farm Security Administration", con el objetivo de apoyar a pequeños granjeros y la regeneración de tierras y comunidades rurales. Este organismo contrató a una serie de fotógrafos con el propósito de documentar aquellas zonas del país más castigadas por la crisis económica. Este proyecto permitió el desarrollo de la fotografía de tipo social, de la mano de profesionales como Walker Evans, Dorothea Lange y Russell Lee, entre otros. El amplio material fotográfico recopilado permitió dar una visión de las duras condiciones en que vivía gran parte de la población rural norteamericana, especialmente al sur del país. El éxito del trabajo documental residió en la fuerza visual de una cruda realidad, en base a una representación sencilla, directa y altamente significativa a nivel moral. Sin ningún tipo de manipulaciones técnicas, alejado de todo contenido pictorialista y sin ánimo de desnaturalizar ninguna instantánea, se logró mostrar la América más mísera.

Palabras clave: Depresión, FSA, fotografía social, Walker Evans, Dorothea Lange, Russell Lee.
\end{abstract}

ABSTRACT. As a result of the economic consequences of fateful "Black Thursday", October 24, 1929, new president Roosevelt proposed four years later a series of socioeconomic measures that would be the base for the "New Deal". Within these measures, there was the creation of the governmental organism "Farm Security Administration", with the objective to support to small farmers and the regeneration of rural communities. This organism contracted a series of photographers in order to document those zones of the country more punished by the economic crisis. This project allowed the development of the social photography, with professionals like Walker Evans, Dorothea Lange and Russell Lee, among others. The ample compiled photographic material allowed showing a vision of the hard conditions that have a great part of the North American rural population, specially in the south of the country. The success of the documentary work resided in the visual force of a crude reality, on the basis of a simple representation, direct and highly significant at moral level. Without technical manipulations, far from the pictorialist content and without intention of denaturing any image, they could show the most miserable America.

Key words: Economic crisis, FSA, social photography, Walker Evans, Dorothea Lange, Russell Lee.

\section{INTRODUCCIÓN HISTÓRICA}

Generalmente, se señala como inicio de la Gran Depresión el 24 de octubre de 1929 (Jueves Negro), con el desplome de la bolsa de Nueva York y la pérdida vertiginosa del valor de las acciones allí cotizadas. Este crack bursátil motivó una fatídica reacción en cadena en el sistema financiero, con 
numerosos bancos que empezaron a tener problemas de solvencia y de liquidez, acentuándose la desconfianza hacia estos a la hora de rembolsar a los depositantes. Para 1932, miles de bancos y más de 100.000 sociedades mercantiles habían quebrado. La producción industrial se redujo a la mitad, el ingreso agrícola decayó en más de un $50 \%$, los salarios bajaron un $60 \%$, la inversión nueva se redujo un $90 \%$, y uno de cada cuatro trabajadores quedó desempleado ${ }^{1}$.

Este colapso económico supuso el inicio de una gran depresión a escala mundial, que llevó a la bancarrota a los productores de materias primas, provocó el estallido de guerras comerciales y la desintegración del sistema bancario.

Las medidas puestas en marcha por el presidente republicano Herbert Hoover todavía incentivaron más la crisis al establecer un intervencionismo agresivo para controlar los precios, especialmente en el campo de la agricultura, impidiendo la recuperación de la economía. El control de precios conllevó la reducción del beneficio empresarial, produciendo la quiebra de muchos negocios y el aumento del desempleo $^{2}$.

La población norteamericana empezó a perder la confianza en Hoover, por este motivo, en las elecciones de 1932, sufrió una severa derrota frente al demócrata Franklin Delano Roosevelt, quien prometió un Nuevo Trato para el pueblo estadounidense. El paquete de medidas económicas y sociales de la Administración de Roosevelt,

\footnotetext{
${ }^{1}$ Una secuencia completa de todas las fechas más relevantes en relación a la Gran Depresión y la puesta en marcha y desarrollo del New Deal, se puede observar en R. GREGORY, Almanacs of American Life. Modern America 1914-1945, New York, 1995, pp. 48-54.

2 D.M. KENNEDY, Entre el miedo y la libertad. Los EE.UU.: de la Gran Depresión al fin de la Segunda Guerra (1929-1945), Barcelona, 2005, p. 111.
}

conocido como el New Deal ${ }^{3}$, a menudo considerado como la solución ante la Gran Depresión, tampoco reactivó la economía, que volvió a entrar en una profunda crisis en 1937, aunque llegó a gozar de una gran popularidad. El New Deal tuvo dos objetivos principales: 1-la reactivación de la economía por vía del consumo y la inversión; 2-el establecimiento de controles bancarios más estrictos para evitar que se pudiera provocar otro crack bursátil en el futuro.

Algunas de las principales propuestas del New Deal ${ }^{4}$ fueron las siguientes:

1- Agricultural Adjustment Act (AAA): marca un nuevo impuesto a la actividad agrícola y entre otras cosas establece que el gobierno pague a los granjeros para que quemen sus cosechas y eliminen el ganado que no podían vender. El gobierno llegó a pagar a los agricultores para que no trabajaran, con la idea de que no aumentara la oferta de productos agrícolas y que, de esta manera, los precios pudieran empezar a subir.

2- Tennesee Valley Authority (TVA): construcción de una red de represas en el área del Río Tennessee, en la región suroriental de los Estados Unidos, con la intención de generar electricidad, controlar las inundaciones y producir fertilizante.

\section{3- National Industrial Recovery Act}

\footnotetext{
${ }^{3}$ Para muchos analistas, como Louis Hartz, Eric Goldman y George Mowry, el New Deal fue una prolongación del reformismo llevado ya anteriormente por otros presidentes, siendo el resultado del pragmatismo de Locke y de las tendencias liberales inherentes a la historia americana. No obstante, para Samuel Lubell, Richard Hofstadter y Dexter Perkins, con el New Deal se dieron pautas novedosas. Para más información, véase C. FOHLEN, La América anglosajona de 1815 a nuestros días, Barcelona, 1976, pp. 166-171.

${ }^{4}$ Para más detalles, sobre las distintas reformas realizadas bajo el paraguas del New Deal, consultar D.M. KENNEDY, Entre el miedo y la libertad. Los EE.UU.: de la Gran Depresión al fin de la Segunda Guerra (19291945), Barcelona, 2005, pp. 303-346.
} 
(NIRA): obliga a la mayoría de las industrias manufactureras a formar cárteles dirigidos por el gobierno, tomando la economía americana un sesgo nacionalcorporativista. Se acortaron las jornadas de trabajo con la intención de emplear a más personas, se elevaron los salarios y se impusieron nuevos costos a los empresarios.

4- Civil Works Administration (CWA): pretende acabar con el desempleo, para ello se contrató a toda clase de trabajadores para realizar tareas como ofrecer espectáculos públicos, organizar archivos, etc. Si bien su labor en actividades como la limpieza de bosques o la reparación de carreteras fue extraordinaria, la CWA no sirvió para reintegrar a los trabajadores en el sector privado ni para estimular la economía.

5- Otras medidas: Civilian Conservation Corps (CCC) pone a hombres jóvenes a trabajar en programas de reforestación y control de inundaciones. Por otra parte, la Ley Wagner de Relaciones Laborales proscribió las prácticas patronales injustas y protegió el derecho de los trabajadores a la negociación colectiva. También, destaca Works Progress Administration (WPA), realizando medidas más efectivas. Fue financiada por impuestos reunidos por el gobierno federal, creándose millones de empleos al emprender la construcción de carreteras, puentes, aeropuertos, hospitales, parques y edificios públicos.

Entre los años 1932 y 1938, gran parte de la agricultura estadounidense del sur y medio oeste fue asolada por una extrema sequía. Todo esto conllevó que la comunidad rural se viera en unas condiciones de extrema pobreza y miseria. La emigración hacia zonas mas prosperas fue la única posibilidad de supervivencia ${ }^{5}$, por eso, en

\footnotetext{
${ }^{5}$ M. A. JONES realiza una interesante introspección en la sociedad norteamericana y sus problemas duran-
}

1935, como parte del New Deal, el Presidente Roosevelt aprobó un programa propuesto por Rexford Guy Tugwell que con el nombre de "Ressetlement Administration" se proponía reasentar a la población de las zonas afectadas.

La responsabilidad básica de esta Agencia Federal incluía préstamos de bajo interés para granjeros pobres, que les posibilitara dejar sus pequeños o marginales terrenos y volverse propietarios de tierras más productivas. Se trasladó a familias de las ciudades donde la economía no las podía mantener y se las instaló en granjas comunales y villas rurales bien ordenadas, donde pudieran sostenerse por si mismas. También, se ocupó de la renovación del suelo a través de la reforestación y de otorgar subvenciones para trabajadores de granjas. A finales de los años 30, el movimiento migratorio abarcó a un millón de personas. El Departamento de Agricultura absorbió esta administración a principios de 1937 y le dio otro estatus legal y un nuevo nombre: "Farm Security Administration" (FSA). Este organismo contrató a una serie de fotógrafos con el propósito de documentar aquellas zonas del país más castigadas por la crisis económica. Esta trágica situación nacional, que vivió los Estados Unidos, permitió un importante desarrollo de la fotografía de tipo social, de la mano de profesionales como Walker Evans, Dorothea Lange, Russell Lee, Ben Shahn y Arthur Rothstein, entre otros.

Los programas del Nuevo Trato de Roosevelt no pusieron fin a la Depresión. Aunque la economía mejoró como resultado de este programa de intervención gubernamental, la recuperación total final-

te la Gran Depresión. M.A. JONES, Historia de Estados Unidos 1607-1992, Madrid, 1996, pp. 428-433. Véase también D.M. KENNEDY, Entre el miedo y la libertad. Los EE.UU.: de la Gran Depresión al fin de la Segunda Guerra (1929-1945), Barcelona, 2005, pp. 201-234. 
mente llegó cuando Estados Unidos reforzó sus sistemas de defensa antes de entrar en la Segunda Guerra Mundial. Este reforzamiento, emprendido para ayudar a los exiliados de la nación en su batalla contra la agresión, absorbió el excedente de mano de obra, incorporándolo a las industrias de guerra y a las fuerzas armadas.

\section{LA CREACIÓN DEL GRAN PRO- YECTO FOTOGRÁFICO DE LA FSA:}

El presidente Roosevelt patrocinó una campaña fotográfica federal para que se tomaran imágenes de las consecuencias de la Gran Depresión económica de su país y de la situación en que vivían los granjeros para luego, a partir de las imágenes, pedir ayuda oficial para los agricultores y ganaderos. Al crear este primer organismo, Rexford Guy Tugwell se propuso redistribuir a las familias de granjeros afectadas por la depresión económica de los años 30 y la gran sequía que se extendió entre 1932 y 1938 en el sur y medio oeste estadounidense. Ya el "crack" de 1929 en la bolsa de Wall Street había bajado el precio de los cereales a menos de la mitad de su anterior valor, empobreciendo drásticamente a la comunidad rural. La idea fue reinstalar a esas familias en zonas más fértiles para que pudieran continuar con su actividad, con lo cual también se evitaría el éxodo de esas personas hacia las grandes ciudades, lo que hubiera provocado importantes aglomeraciones en las mismas.

Tugwell intentó concienciar a los políticos sobre la necesidad de buscar recursos para llevar a cabo su tarea, creando un subdepartamento al que llamó "Historical Section". Puso al frente del mismo a Roy Emerson Stryker, siendo su objetivo documentar fotográficamente las actividades de este organismo, como medio para dar a conocer una delicada situación social y a partir de ahí obtener de las autoridades los fondos necesarios.
La mayoría de los trabajos transcurrieron en el Sureste de Estados Unidos, tanto en el ámbito rural como en el urbano. Se le pidió a cada fotógrafo que estudiara y tomara conciencia de la situación económica y social de cada una de las zonas y de cada sujeto o ámbito que se fuera a retratar. Stryker invitó a que sus fotógrafos transmitieran la significación humana e histórica de este drama, para lo que les dio plena libertad de imagen. Stryker planteó este proyecto con la idea de conformar una enciclopedia fotográfica de la agricultura norteamericana ${ }^{6}$. Desde 1944, estas fotografías pueden ser consultadas en el archivo de la biblioteca del Congreso de Estados Unidos.

La importancia histórica de la FSA consiste en que permitió documentar a la América rural, en una época marcada por la pobreza y la miseria, durante un periodo comprendido entre 1935 y 1943, a nivel sociológico, artístico, histórico y periodístico. Stryker dirigió este grupo de fotógrafos durante ocho años, produciendo más de 270.000 fotografías. Para Stryker, lo más importante era que todos los fotógrafos tuvieran en común un profundo respeto por el ser humano. Lo producido debía ser fotoperiodismo, ya que sus fotografías tenían que documentar la situación del momento, sin deformar la realidad de los años 30.

El empecinamiento de Striker en subestimar las cualidades artísticas de las fotografías que le enviaban periódicamente los profesionales que había contratado, le generó muchos problemas ${ }^{7}$ con algunos de ellos, especialmente con Dorothea Lange y Walker Evans. A pesar de estas inevitables desavenencias, los fotógrafos de la FSA

\footnotetext{
${ }^{6}$ J. PULTZ, Fotografía americana del siglo XX, Barcelona, 1991, p. 26.

${ }^{7}$ JAN ARROW, Dorothea Lange, London, 1985, p. 4. Véase también J. SZARKOWSKI, Walker Evans, 1971, p. 15.
} 
crearon un trabajo de alto valor estético, pero lamentablemente y por la indolencia del mismo Stryker, se perdió casi un 40 por ciento de esa obra.

Aunque el proyecto fotográfico de la FSA constituyó el mayor plan de documentación fotográfica jamás realizado en Estados Unidos, no obstante, no era la primera vez que se recurría a la fotografía como instrumento para sensibilizar a la población sobre problemas sociales determinados. Por ejemplo, Jacob Riis ${ }^{8}$ (1849-1914) emprendió ya en 1880 una labor fotográfica sobre las precarias condiciones de vida existentes en algunos barrios de New York. Por otra parte, Lewis Hine ${ }^{9}$ (1874-1940) abordó la explotación infantil en los albores del desarrollo industrial americano. Aunque, ambos consiguieron ciertos resultados positivos a nivel social, su trabajo no pasó de ser privado y personal. A diferencia de estas limi-

\footnotetext{
${ }^{8}$ Sobre este autor, resultan de interés las siguientes publicaciones: Y. BONNIE, Rediscovering Jacob Riis: exposure journalism and photography in turn-of-thecentury New York, New York, 2007; T. BUK-SWIENTY, The other half: the life of Jacob Riis and the world of immigrant America, New York, 2008; J. RIIS, Jacob Riis, London, New York, 2001; J. RIIS, Jacob A. Riis: socialreporter med kamera $=J a c o b$ A. Riis: social reporter with camera, Laholm, 1987; J. RIIS, The complete photographic work of Jacob A. Riis, New York, London, 1981; J. RIIS, Jacob Riis revisited; poverty and the slum in another era, Garden City, N.Y., 1968.

${ }^{9}$ En relación a este fotógrafo, resultan de interés para consulta los siguientes manuales: V.P. CURTIS, Photography and reform: Lewis Hine \& the National Child Labor Committee, Milwaukee, Wis., 1984; G. DIMOCK, Priceless children: American photographs 1890-1925: child labor and the pictorialist ideal, Greensboro, N.C.; Seattle, Wash., 2002; R. FREEDMAN, Kids at work: Lewis Hine and the crusade against child labor, New York, 1994; L.W. HINE, Lewis Hine: photographs of child labor in the new South, Jackson, 1986; L.W. HINE, America \& Lewis Hine: photographs 1904-1940: [exhibition], New York, 1977; K. LIGHT, Witness in our time: working lives of documentary photographers, Washington, 2000; J. RAEBURN, A staggering revolution: a cultural history of thirties photography, Chicago, 2006; K. SAMPSELL-WILLMANN, Lewis Hine as social critic, Jackson, 2009; M. PANZER, Lewis Hine, London, New York, 2002.
}

tadas y anecdóticas iniciativas, ahora será una administración estatal la que se interesará por la utilización de la fotografía como instrumento válido para el registro de la realidad.

El primer fotógrafo que trabajo bajo las órdenes de Stryker fue su ayudante y alumno en la Universidad de Columbia, Arthur Rothstein. Más tarde, se añadirían los nombres de Walter Evans, Dorothea Lange, Ben Shahn, Carl Mydans, Russell Lee, John Vachon, Marion Post Wolcott, John Collier y Jack Delano, entre otros.

La FSA ${ }^{10}$ abrió un nuevo sendero para la fotografía, afianzándose el concepto de documentación fotográfica. En definitiva, se pudo recopilar un extraordinario trabajo de carácter social con la veintena de profesionales que pasaron por la "Historical Section" de esta organización. En definitiva, se desarrolló una aportación caracterizada por los parámetros de realidad, evidencia, autenticidad y actualidad. Fue Roy Stryker el que orientó a estos profesionales en torno a los anteriores parámetros conceptuales, aunque también se crearon numerosas discrepancias en torno a la base programática del proyecto. Para muchos de estos fotógrafos, el período comprendido de su paso por la FSA supuso la creación de sus mejores imágenes.

\footnotetext{
${ }^{10}$ Resultan de interés las siguientes publicaciones relacionadas con el tema: S. COHEN, The likes of us: America in the eyes of the farm security administration, Boston, 2009; C.S. DOTY, Acadian hard times: the Farm Security Administration in Maine's St. John Valley, 19401943, Orono, Me., 1991; FARM SECURITY ADMINISTRATION, From shore to shining shore: photographs of the United States, 1935-43, from the Farm Security Administration, York, England, 1978; A. FISHER, Let us now praise famous women: women photographers for the U.S. government, 1935 to 1944, London; New York, 1987; G. MORA, FSA: the American vision, New York, 2006.
} 


\section{LOS FOTÓGRAFOS DE LA “AMÉ- RICA MÁS MÍSERA":}

3.1- Walker Evans ${ }^{11}$ (1903-1975) viaja en 1922 a París para seguir sus estudios en la Sorbona, pero con la idea de hacerse escritor y mezclarse con la vida intelectual de esta capital. Influenciado por poetas franceses del XIX, ve en la fotografía un medio para adaptar la visión de poeta y mostrar meticulosamente la América cotidiana contemporánea.

En 1932, ilustra "The Crime of Cuba" de Carleton Beans, una denuncia del régimen de Batista, para lo que hizo una serie de fotografías, donde mezcla retratos con detalles arquitectónicos y escenas callejeras. Entre los años 1935 y 1936, durante 18 meses, trabaja para la "Farm Security Administration". Junto a James Agee ${ }^{12}$ convivió seis semanas con una familia de aparceros de una granja de Alabama. Evans los fotografió mostrando su vida de forma simple y directa, pero con cierto distanciamiento, aunque logró retratos de gran dignidad. Junto con los textos de Agee, las fotografías se publicaron en el libro "Let Us Now Praise Famous Men" en 1941.

Este fotógrafo negó cualquier implicación política y social de su trabajo, de hecho, sus imágenes estuvieron exentas de la dramatización propia del contexto, sim-

-

${ }^{11}$ Para profundizar sobre la obra de este fotógrafo, véase W. EVANS, Walker Evans at work: 747 photographs together with documents selected from letters, memoranda, New York, NY, 1994; W. EvANS, Walker Evans: public photographs 1935-1937, Buffalo, N.Y., 1998; W. EVANS, Walke Evans 1903-1975, New York, 2000; W. EvANS, Walker Evans: lyric documentary, Göttingen, 2006; G. MORA, Walker Evans: the hungry eye, New York, 1993; J.R. Mellow, Walker Evans, New York, 1999; B. RATHBONE, Walker Evans: a biography, Boston, 1995; L. SANTE, Walker Evans, London, 2001.

${ }^{12}$ M. BRIX, Walker Evans, America, New York, 1991, p. 24. plemente planteó un "estilo documental"13. Se encontraba más cerca de Eugene Atget que de Lewis Hine, más inspirado por Mathew Brady que por Jacob Riis. A nivel compositivo, buscó un punto de atención en la imagen, dirigiendo la mirada del espectador hacia un espacio cargado de densa información. Evans reivindicó un lenguaje propio para la fotografía, lejos de cualquier recurso técnico que minara un enfrentamiento directo con el objeto.

3.2- Aunque Dorothea Lange ${ }^{14}$ (18951965) se inició estudiando en la Clarence White School, con un marcado corte pictoralista, posteriormente, su salida a la calle como reportera marcaría definitivamente lo que serían las señas de identidad de su trabajo. En 1933-1935, comienza a fotografiar la calle, además de frecuentar el grupo $\mathrm{f} / 64$.

Su obra más conocida se desarrolla en los años 30, años de la depresión, trabajando desde 1935 hasta 1940 para la FSA. En 1938, comienza a preparar junto a su marido "A American Exodus, A Record of Human Erosion", libro que recoge textos y fotografías sobre la migración motivada por la depresión.

${ }^{13}$ JERRY L. THOMPSON, Walker Evans at Work, London, 1984, p. 12.

${ }^{14}$ En torno a esta fotógrafa, encontramos las siguientes publicaciones: P. BORHAN, Dorothea Lange: the heart and mind of a photographer, Boston, 2002; M. DURDEN, Dorothea Lange, London; New York, 2001; L. GORDON, Dorothea Lange: a life beyond limits, London; New York, 2009; T.T. HeYMAN, Dorothea Lange: American photographs, San Francisco, 1994; J. KeLLER, Dorothea Lange: photographs from the J. Paul Getty Museum, Los Angeles, 2002; D. LANGE, Dorothea Lange: Farm Security Administration photographs, 1935-1939: from the Library of Congress, Glencoe, Ill., 1980; D. LANGE, The photographs of Dorothea Lange, Kansas City, Mo., 1995; M MELTZER, Dorothea Lange: life through the camera, New York, N.Y., 1985; E. PARTRIDGE, Restless spirit: the life and work of Dorothea Lange, New York, 1998. 
Al igual que Walker Evans, con quien comparte esa mirada concisa y digna, recorre el país documentando la precaria situación en la que viven los aparceros. No obstante, a diferencia de Evans, sus personajes ganan más humanidad, acercándose a ellos de manera emocional y aportándoles un aire de heroísmo. Para Peter Galassi, "Como Evans, Lange había alcanzado una apariencia madura y un estilo antes de entrar en la FSA, pero la similitud entre ambos acaba ahí. Evans veía a la América contemporánea como si él fuera un historiador desinteresado que examinara los restos de una civilización desaparecida. Lange era una idealista apasionada, que pretendía provocar el cambio social a través de su obra. (Tuvo éxito, por ejemplo, cuando la publicación de Migrant Mother provocó una rápida ayuda al campamento donde se tomó la foto)." ${ }^{\prime 15}$

$\mathrm{Su}$ trabajo viene marcado por un fuerte sentimiento humano y una conciencia social unida a una lucha incansable por la igualdad de la mujer. En homenaje a las mujeres que fotografió, llegó a comentar lo siguiente: "Estas son las mujeres del territorio americano. Ellas demuestran un fuerte valor. Ellas son las raíces de nuestro país. Ellas viven en nuestras llanuras, praderas, desiertos, montañas, valles y ciudades. Ellas no son mujeres para anuncios de belleza y moda, ni son parte de los anuncios del estilo de vida americano. Ellas son en si mismas un gran estilo americano. Ellas viven con valentía y propósito, siendo parte de nuestra tradición." ${ }^{\prime 16}$

Dorothea Lange se sintió comprometida con la necesidad de transmitir un mensaje y una idea de tipo social. Su objetivo

${ }^{15}$ P. GALASSI, Fotografía americana 1890-1965, Valencia, 1995, p. 22.

${ }^{16}$ Dorothea Lange. Citado en KeItH F. Davis, The photographs of Dorothea Lange, Kansas City, 1995, p. 58.
}

primordial era reflejar el drama humano, antes que interesarse por los aspectos formales del tema. Creía firmemente en el poder de información y persuasión que sus imágenes podían poseer. Ben Shahn como Dorothea Lange creían ciegamente en el poder de las imágenes para conmocionar a un público determinado.

3.3- Russell Lee ${ }^{17}$ (1903-1986) realiza fotografías inmiscuyéndose entre la gente con suma naturalidad, como si ninguno de sus retratados se diera cuenta de su presencia. En 1936, forma parte del grupo de Roy Stryker.

Este profesional fue responsable de algunas de las imágenes-icono de la Gran Depresión. Su trabajo fue ampliamente prolífico, realizándose retratos de todo tipo. $\mathrm{Su}$ objetivo prioritario fue mostrar la pobreza, pero tratada con la mayor dignidad posible. Buscaba que sus imágenes tuvieran un efecto directo en las clases políticas, con el objetivo de obtener fondos gubernamentales para superar esta situación dramática. Russell Lee había aprendido y estudiado los trabajos de otros fotógrafos de Arkansas, como Arthur Rothstein y Carl Mydans $^{18}$. In 1939, realiza la imagen titulada "Migrant Child Returning Home from Fields, Prague, Oklahoma", siendo una de las mejores escenas representativas de la explotación infantil en el trabajo del campo. Dentro de su repertorio, encontramos principalmente granjeros, aparceros y trabajadores emigrantes, personajes que fue cono-

\footnotetext{
${ }^{17}$ En relación a su obra fotográfica, se pueden consultar las siguientes referencias: M.J. APPEL, Russell Lee: a centenary exhibition: Russell Werner Lee, the man who made America's portrait, San Marcos, Texas, 2003; R. LEE, Russell Lee, photographer, Dobbs Ferry, New York, 1978; R. LEE, Russell Lee photographs: images from the Russell Lee photograph collection at the Center for America, Austin, Texas, 2007; R. LEE, The photographs of Russell Lee, Washington, D.C.; London, UK, 2008.

${ }^{18}$ Sobre este autor, véase C. MYDANS, Carl Mydans, photojournalist, New York, 1985.
} 
ciendo y retratando mientras cruzaba el territorio norteamericano. Se especializó principalmente en dos zonas: San Augustine, Texas, en 1939; y Pie Town, New Mexico, en 1940. Ambas aparecen representadas en la colección Russell Lee de la Wittliff Gallery.

3.4- Ben Shahn ${ }^{19}$ (1898-1969) había nacido en Lituania, pero su familia tuvo que emigrar en 1906 a los Estados Unidos por motivos políticos. Será en Nueva York donde comienza su carrera artística, realizando sus primeras propuestas como tipógrafo y diseñador gráfico, uniendo los potenciales comunicativos del texto con la imagen. Pronto, fue recomendado por Walker Evans para formar parte del grupo de fotógrafos de la FSA.

Se inclinó por captar la expresión, los gestos y la mímica de la gente, es decir, ese instante preciso, que representa la mayor expresividad de una suma de momentos, lo que le hacía lógicamente un admirador de Henry Cartier-Bresson. Utilizó una cámara Leica, de acuerdo a los consejos aportados por Walter Evans ${ }^{20}$, con un objetivo situado en ángulo recto, de este modo, captaba situaciones espontáneas, en personajes que no se suponían fotografiados. Su objetivo fue realizar una fotografía de tipo objetiva, alejada de todo rasgo de sensacionalismo.

Destacó también por su actividad pictórica, quedando reconocido por sus trabajos murales cercanos al realismo social, siendo, por ejemplo, el ayudante de Diego

\footnotetext{
${ }^{19}$ Para recabar mayor información sobre el tema, se pueden consultar los siguientes catálogos: F.K. POHL Ben Shahn, San Francisco, Calif., 1993; B. SHAHN, Ben Shahn; photographer; an album from the thirties, New York, 1973; B. SHAHN, The photographic eye of Ben Shahn, Cambridge, Mass., 1975; B. SHAHN, Ben Shahn: an artist's life, New York, 1998; B. SHAHN, The photographs of Ben Shahn, Washington, D.C., 2008.

${ }^{20}$ G. MORA; JOHN T. HILL, Walker Evans: the Hungry Eye, London, 2004, p. 134.
}

de Rivera con motivo de la realización del mural del Rockefeller Center. Se caracterizó por la denuncia de las injusticias sociales, desarrollando un arte basado en numerosos reportajes documentados. En este sentido, muchos de sus murales abordaban temas relacionados con el anti-semitismo y la pobreza de las clases trabajadoras, así que la oportunidad que se le brinda para documentar la miseria del sur de Norteamérica se amolda perfectamente a sus condiciones ideológicas. Durante la década de los años 30, Ben Shahn es el referente y el líder del realismo social americano.

3.5- Arthur Rothstein ${ }^{21}$ (1915-1985) había sido estudiante de Roy Stryker a principios de los años 30 en la Universidad de Columbia. En 1935, prepara un conjunto de fotografías para un libro sobre la agricultura en los Estados Unidos, no obstante, el libro nunca fue completado, ya que Stryker le contrataría para trabajar en la "Resettlement Administration".

Su labor dentro de este organismo duró unos cinco años, documentando la vida de los granjeros de Arkansas, quienes tuvieron que realizar un largo camino hacia el Parque Nacional de Shenandoah para ser allí recolocados por la RA. Los siguientes viajes le llevaron en 1936 a fotografiar la famosa serie "Dust Bowl", donde se documentaba un conjunto de catastróficas tormentas de polvo, que causaron enormes pérdidas en las praderas americanas y canadienses durante los años 30 . Será en el condado de Cimarron County, donde realiza una de sus imágenes más conocidas: un hombre con sus dos hijos en una tormenta

\footnotetext{
${ }^{21}$ La obra de este fotógrafo, se encuentra perfectamente recogida en las siguientes ediciones: A. ROTHSTEIN, The depression years, New York, 1978; A. ROTHSTEIN, Photojournalism, Garden City, N.Y., 1979; A. ROTHSTEIN, The American West in the thirties, New York, 1981; A. ROTHSTEIN, Arthur Rothstein's America in photographs, 1930-1980, New York, 1984; A. ROTHSTEIN, Documentary photography, Boston, 1986.
} 
de polvo. Posteriormente, también mostró la vida en los ranchos de ganado de Montana.

Especialmente, destaca el trabajo sobre los residentes de Gee's Bend, Alabama, que permitió dos aspectos básicos a la FSA. Por una parte, documentar una comunidad, con unos residentes aislados y primitivos, cuyo habla, hábitos y patrones culturales tenían una fuerte relación con su origen africano. Por otra parte, estudiar a los residentes como víctimas de la esclavitud y del sistema de arrendamiento rural en conexión con las antiguas plantaciones. Estos dos estudios fueron la base para la aplicación de una serie de medidas basadas en la formación y la ayuda financiera.

A diferencia de la mayoría de las fotografías realizadas para la RA y la FSA, los habitantes de Gee's Bend no posaron en ningún momento como víctimas. Estas fotografías no mostraron un trabajo inhumano en torno al cultivo y la recolección, sino que únicamente ofrecían una visión agrícola. Ciertamente, los habitantes de Gee's Bend no se sintieron muy cómodos ante la presencia de Rothstein. Ante todo el objetivo del fotógrafo fue demostrar que esta gente también tenía una dignidad en todos los ámbitos de su vida, de ahí que se realizaría una apuesta por esta condición humana.

3.6- Otros fotógrafos destacados de la RA-FSA fueron Marion Post Wolcott ${ }^{22}$ (1910-1990), que reflejó la vida y costumbres de las clases pudientes que se movían en el mismo entorno que las clases menos privilegiadas. Una propuesta gráfica, que no fue del gusto de Stryker, totalmente en contra de buscar confrontaciones visuales de carácter clasista; Jack Delano ${ }^{23}$ (19141997) estuvo influenciado, como muchos fotógrafos de la FSA, por Walter Evans ${ }^{24}$. Su objetivo fue realizar imágenes fulminantes y singulares, con un fuerte contenido emocional; John Collier (1913-1992) se posicionó notablemente en contra de que estos trabajos documentales se pudieran realizar desde una visión artística, afirmando que su único sentido era potenciar un trabajo puramente documental.

${ }^{22}$ Véase las siguientes referencias para recabar mayor información: F.J. HURLEY, Marion Post Wolcott: $a$ photographic journey, Albuquerque, New Mexico, 1989; M.P. WolcotT, Marion Post Wolcott: FSA photographs, Carmel, California, 1983; P. HENDRICKSON, Looking for the light: the hidden life and art of Marion Post Wolcott, New York, 1992; M.P. WOLCOTT, The photographs of Marion Post Wolcott, Washington, D.C., London, 2008.

${ }^{23}$ Sobre este fotógrafo, resulta de interés J. DELANO, Photographic memories, Washington, 1997.

${ }^{24}$ P. GALASSI, Walker Evans \& Company, New York, 2004, p. 24. 


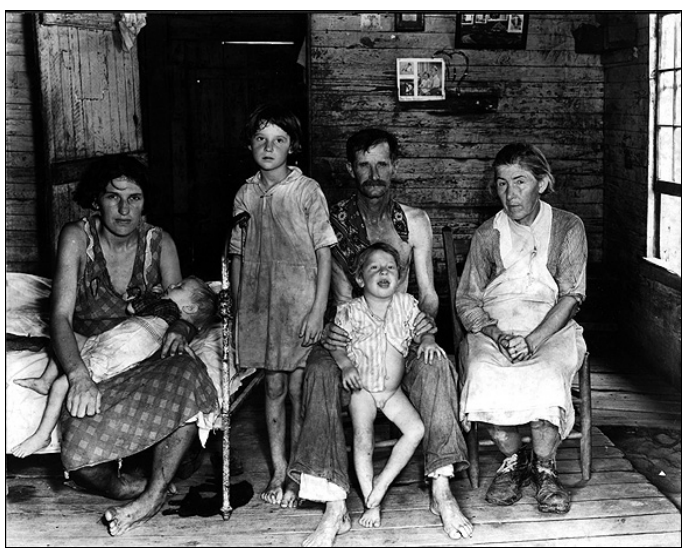

- Fig. 1. Walker Evans, "Sharecropper's Family", 1936.

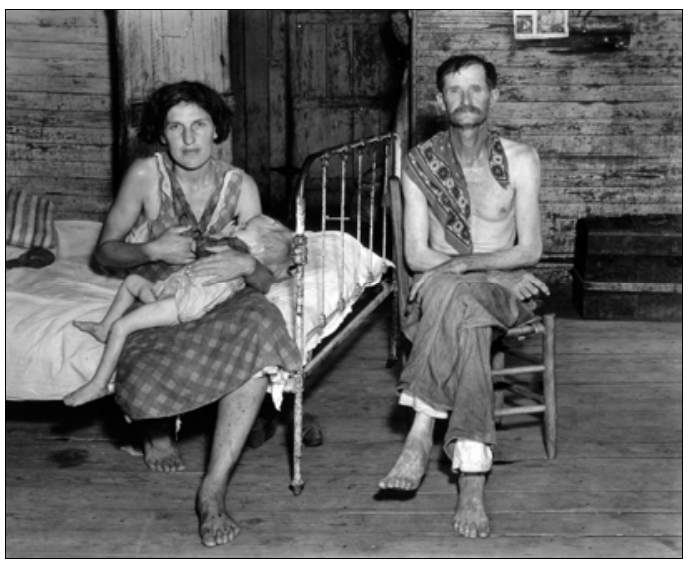

- Fig. 2. Walker Evans, "Sharecropper's Family", 1936.

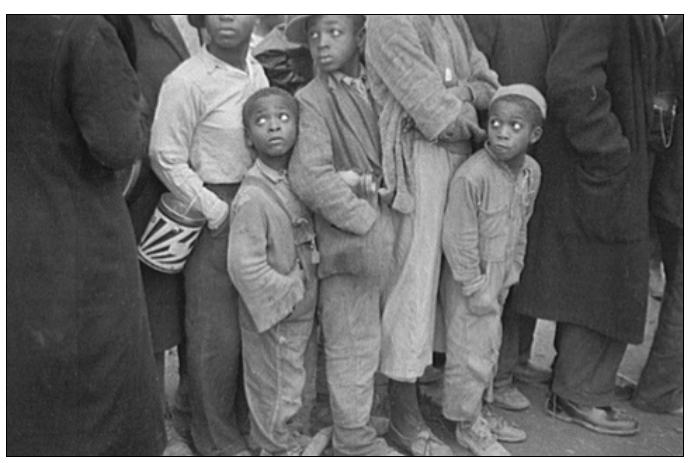

- Fig. 3. Walker Evans, "No Known Restrictions: Flood Refugees", 1937.

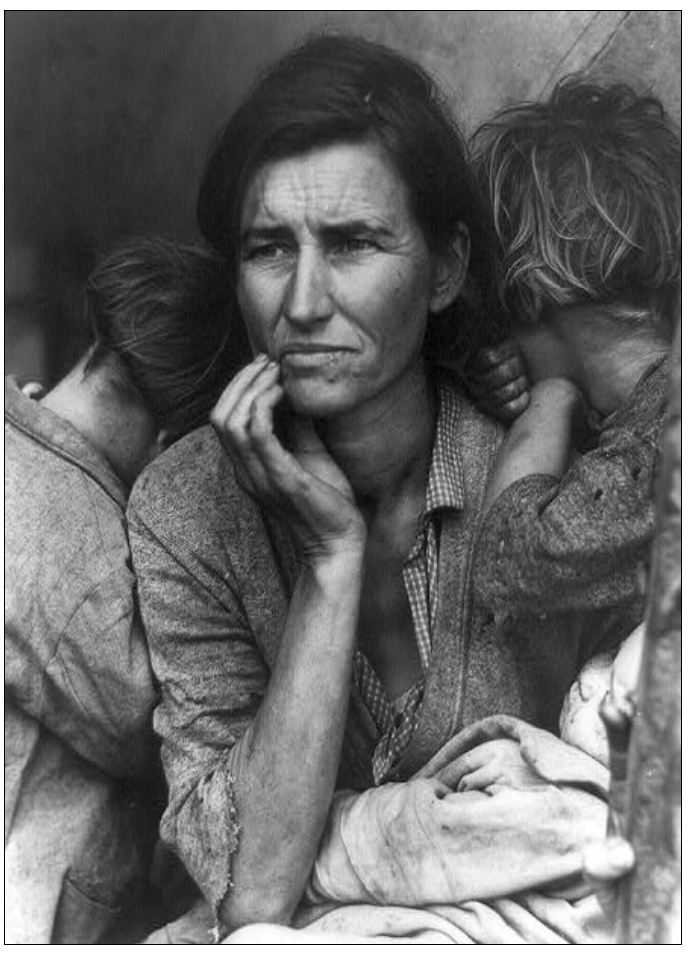

- Fig. 4. Dorothea Lange, "Migrant Mother", 1936.

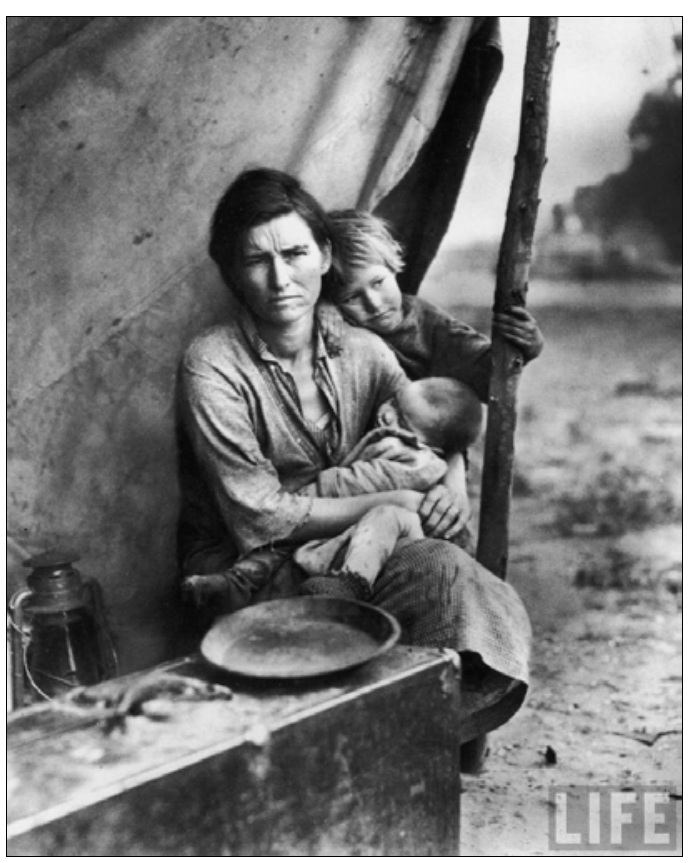

- Fig. 5. Dorothea Lange, "Migrant Mother", 1936. 


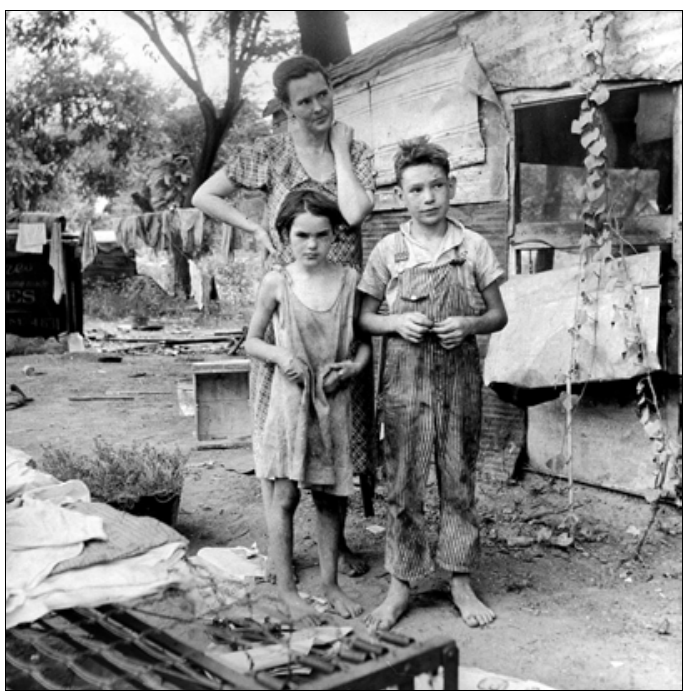

- Fig. 6. Dorothea Lange, "People living in miserable poverty. Elm Grove, Oklahoma County, Oklahoma", 1936.

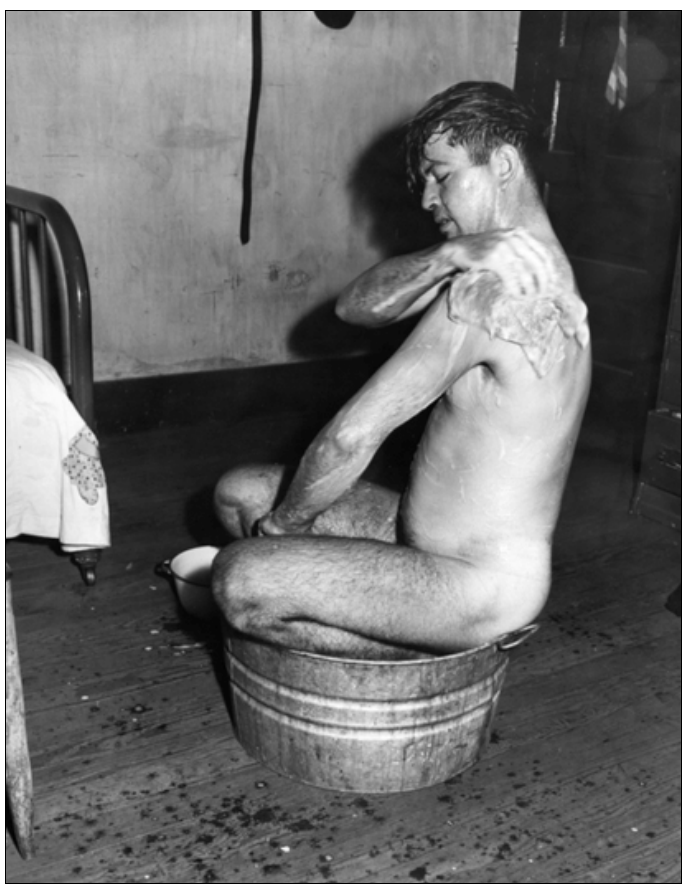

- Fig. 7. Russell Lee, "Life in a coal mining community", finales de los años 30 .

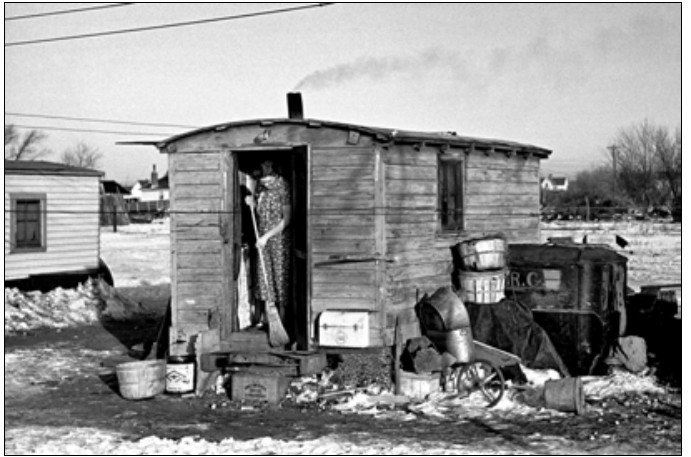

- Fig. 8. Russell Lee, "Home Sweet Hovel", 1936.

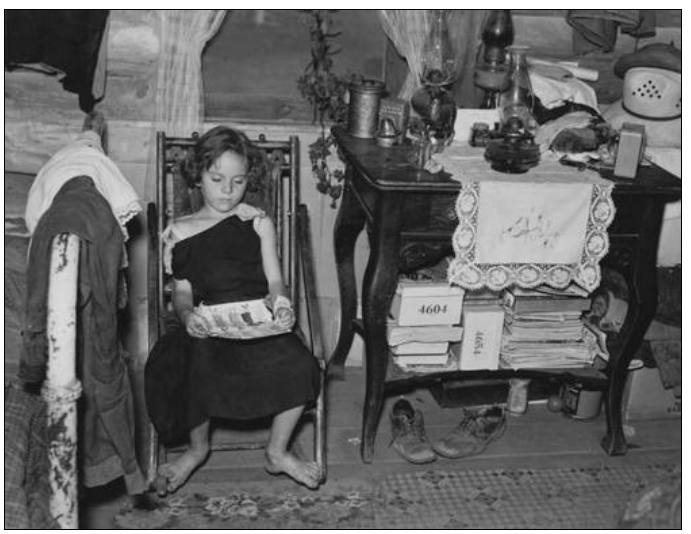

- Fig. 9. Russell Lee, “Farmer's Daughter Drought Stricken North Dakota", 1936.

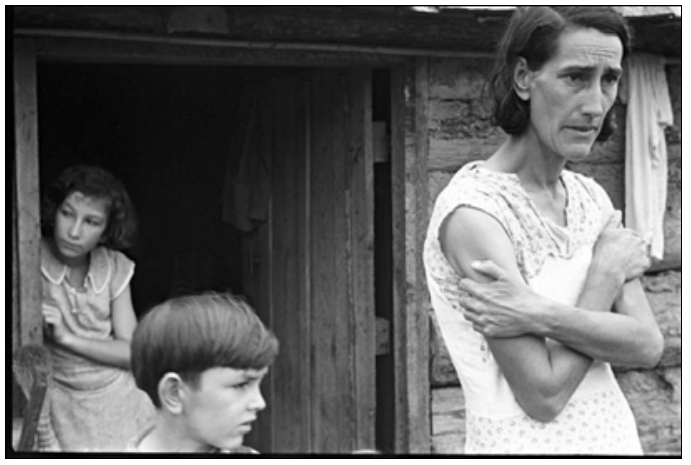

- Fig. 10. Ben Shahn, "Boone County, Arkansas. The family of a Resettlement Administration client in the doorway of their home", 1935. 


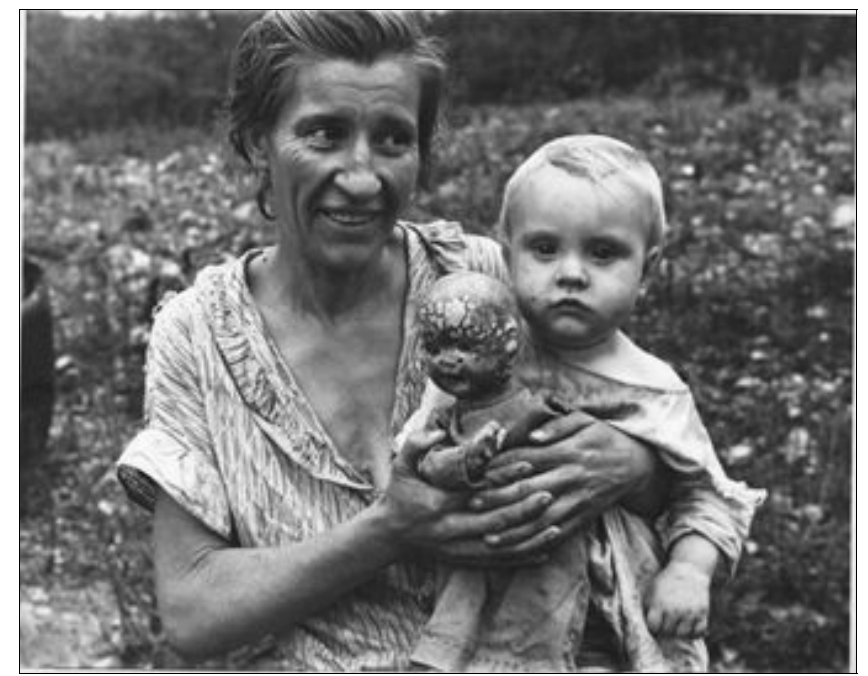

- Fig. 11. Ben Shahn, "Wife and Child of a Sharecropper (Mrs. Mulhall), Ozark Mountains, Arkansas", 1935.

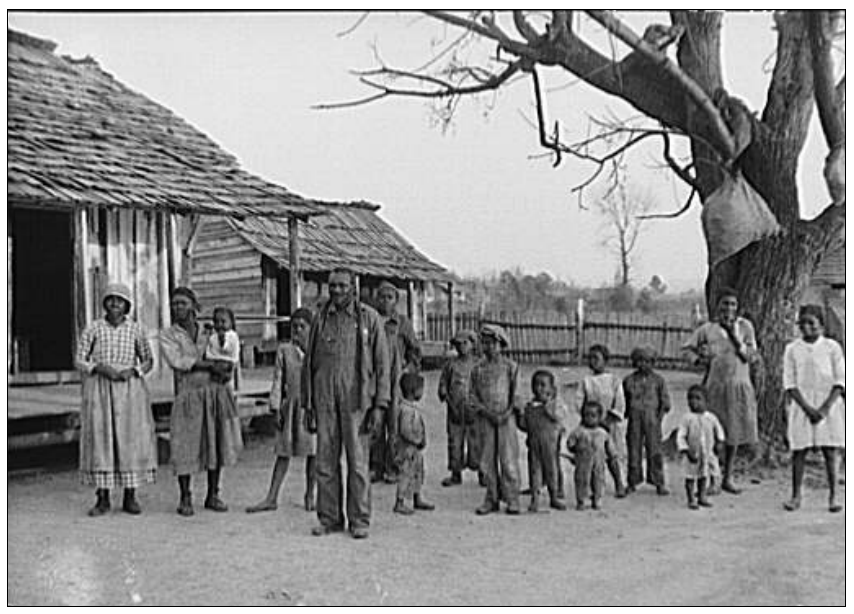

- Fig. 12. Arthur Rothstein, “Negroes, descendants of former slaves of the Pettway Plantation, Gees Bend, Alabama", 1937.

Fuentes figuras:

1- http://theoriedesimages.files.wordpress.com/2009/06/trodd-walker-evans-01.jpg

2- http://www.elfotografico.com/wp-content/uploads/2009/12/3g04832u_0.jpg

3- http://farm1.static.flickr.com/205/472004201_40bd49165c.jpg

4- http://glenclous.files.wordpress.com/2008/10/dorothea-lange.jpg

5- http://blogs.denverpost.com/captured/wp-content/photos/timelife011.jpg

6- http://www.shorpy.com/files/images/3c29107u.preview.jpg

7-: http://drx.typepad.com/psychotherapyblog/images/2007/08/31/russell_lee_photo_2.jpg

8- http://www.shorpy.com/files/images/8a21443u1.preview.jpg

9- http://www.moma.org/collection_images/resized/463/w500h420/CRI_61463.jpg

10-: http://johnedwinmason.typepad.com/.a/6a0112791cb10528a401310f7bfa12970c-500wi

11- http://www.christies.com/lotfinderimages/d52367/d52367601.jpg

12- http://historymatters.gmu.edu/mse/photos/images/pettway1.jpg 